Brazilian Journal of Political Economy, vol. 42, $n^{\circ}$ 1, pp. 5-24, January-March/2022

\title{
The global financial crisis and its effects on the international monetary funds
}

\author{
A crise financeira global e seus efeitos sobre \\ os fundos monetários internacionais
}

COSIMO MAGAZZINO*

MARCO MELE**

RESUMO: Este artigo tem como objetivo analisar as inovações introduzidas nas funções do Fundo Monetário Internacional no contexto da crise econômica e financeira de 2008 . Isso promoveu uma ação que teve como objetivo fortalecer a função de vigilância por meio da adoção da Vigilância Integrada. Assim, a par da condicionalidade tradicional baseada na implementação a posteriori de políticas econômicas adequadas, introduziu-se também um critério de condicionalidade ex ante nos ramos de precaução ou em função das características econômicas do país a financiar. No que diz respeito à condicionalidade tradicional, será perguntado se o FMI adotou uma abordagem menos abrangente do que seu papel.

PALAVRAS-CHAVE: IMF; taxa de câmbio; reforma da governança; função de vigilância.

ABSTRACT: This paper aims to analyze the innovations introduced in the functions of the International Monetary Fund in the context of the 2008 economic and financial crisis. This promoted an action that aimed to strengthen the surveillance function through the adoption of the Integrated Surveillance. Thus, alongside the traditional conditionality based on an a posteriori implementation of adequate economic policies, a criterion of ex ante conditionality in the precautionary branches was also introduced or based on the economic characteristics of the country to be financed. Concerning traditional conditionality, it will be asked whether the IMF has adopted a less extensive approach than its role.

KEYWORDS: IMF; exchange rate; governance reform; surveillance function.

JEL Classification: E42; F02; F42; G20.

\footnotetext{
* Department of Political Sciences, Roma Tre University, Roma/Italy. E-mail: cosi-mo.magazzino@uniroma3.it. Orcid: https://orcid.org/0000-0002-3176-9838.

** Department of Political Sciences, Roma Tre University, Roma/Italy. E-mail: mar-co.mele@uniroma3.it. Orcid: https://orcid.org/0000-0002-1477-1071. Submitted: 26/October/2020; Approved: 1/April/2021.
} 


\section{INTRODUCTION}

The financial crisis started in the USA in 2007, which then became a world economic recession, hit many countries, leading the International Monetary Fund (IMF) to take a series of measures to restore financial markets order. The IMF's interventions in a first phase, between the end of 2008 and the beginning of 2009, saw Eastern European countries as the beneficiaries, the most fragile and exposed region of the recession. Among these, we can mention Hungary, Romania and Ukraine, to which the IMF provided resources of about 45 billion dollars. Interventions of the same type but less consistent were also carried out for Belarus, Iceland, Latvia and Georgia. In all these cases, the granting of aid was subordinated to the reaching of an agreement with the governments for the implementation of programs that aimed at: 1 ) restoring public and trade deficits to sustainable levels; 2) restoring confidence and create the conditions for the recovery of capital inflows; 3 ) strengthening the domestic banking sector. In the spring of 2009, the IMF's action was enhanced with a new instrument, the Flexible Credit Line (FCL). It is a credit line that can be used freely by the beneficiary country and is not conditioned by compliance with an economic and financial stability program agreed with the IMF. The FCL is not granted to help a country affected by the recession or speculative attacks on currency or public debt, but to prevent this type of situation in advance. To obtain an FCL loan, the beneficiary country must, however, boast positive and continuous macroeconomic performances over time, such as: GDP growth with low inflation, control of public debt, limited current account deficit, and well-capitalized banking sector. Thanks to these prerogatives, in April 2009, Mexico was the first country to receive a $\$ 47$ billion FCL, the single most significant intervention in the history of the IMF so far. A few weeks later it was Poland that received a $\$ 20.6$ billion FCL, a country that during previous years had shown excellent macro-level performances and the implementation of reforms and initiatives based on entering the Euro area. During 2010, the long wave of the crisis hit the weakest economies in the Euro area. This raised many concerns due to the risk of "contagion" to other countries of the monetary union with the possibility of a consequent destabilization of the common currency. In the spring of 2010 , the IMF approved a $€ 30$ billion loan as part of a package of aid to Greece with a total amount of $€ 110$ billion in collaboration with the European Union. At the end of 2010, it was Ireland's turn to receive $€ 22.5$ billion from the IMF. Again, this was a coordinated intervention with the European authorities for a total of $€ 85$ billion. In May 2011, the IMF granted aid to Portugal, amounting to around $€ 26$ billion.

Despite the interventions made, there have been numerous criticisms on the IMF. They have highlighted its substantial failure in identifying the most appropriate surveillance to avoid financial crisis. Among the doubts on the actual work of the IMF, some underline the lack of interventions in avoiding systemic risk. It was necessary to warn member countries of the dangers they were developing in financial markets. The weakness of the Fund's action has favored a reform process that has involved 
three areas: the governance, the supervisory function, and the financial assistance. Thus, in this paper, we will critically examine the latter two reforms.

\section{THE POST-CRISIS SURVEILLANCE FUNCTION}

Responding to the requests from the G-20 to strengthen the ability to analyze the risks that could undermine the stability of the international economic and financial system, in 2010 the IMF launched a profound debate on what were the most appropriate tools to reconstruct the systemic consequences of policies internal resources of each member. The debate started on the idea of an action that must take place in the broader perspective, not only limited to the effects on national economies (IMF, 2010). The need for greater integration between macroeconomic and financial analysis was also underlined to highlight the links between the two sectors and between bilateral and multilateral surveillance. This transformation process culminated in 2012 with the adoption of the Integrated Surveillance Decision (ISD), with which the IMF set the ambitious goal of "improving the quality, evenness, and effectiveness of the IMF's surveillance, as well as better integration of all surveillance activities" (IMF, 2012). The ISD proposed a strengthening of bilateral surveillance through the assessment of the repercussions on national economies that could derive from policies implemented by other states (inward spillovers) and, conversely, of the effects on third countries of national policies (outward spillovers). In the performance of bilateral surveillance activity, the notion of "external stability" or "balance of payments stability" remains central. However, despite the changes introduced by the decision on integrated surveillance, the implicit limit to the definition of systemic stability remains, anchored to the complex of currency relations, and is not able to take into account the importance assumed by financial markets in favoring the transmission of conditions of instability between national economic systems, which do not always produce effects on the value of the currencies of the States concerned (Adinolfi, 2012).

Furthermore, new analysis tools have been prepared to capture the links between national economies and the main transmission channels through which Members' internal policies are likely to affect the economic processes of third States. In particular, three instruments are currently contributing to multilateral surveillance.

The first is the bilateral control action, which is thus integrated into the exercise of the multilateral one. For each Member, the Secretariat is called to examine, and the Executive Committee to discuss, the impact and spillover effects of national policies on the effective functioning of the international monetary system (ISD, par. 26). The relevance of this provision can be appreciated above all in consideration of the limits placed on the scope of bilateral surveillance by the definition of systemic stability: the economic, financial and currency policies are here analyzed independently of their effects on the currency markets, for a more general consideration their impact also on capital movements and cross-border liquidity transfers (Adinolfi, 2012). The second tool (ISD, par. 30) takes up the reports periodically published by 
the Secretariat (such as the World Economic Outlook, the Global Financial Stability Report, the Fiscal Monitor, the External Sector Report), in consultation with Members and other international organizations.

Finally, a third tool is given by the multilateral consultations that can be promoted on the initiative of the Director-General regarding general or individual country issues (ISD).

The strengthening of the supervisory function also concerned the financial sector. The first step in this direction was made in September 2010 with the Executive Committee's decision 14736-(10/92) to report the Financial Sector Assessment Program (FSAP) in the context of bilateral supervision for states whose financial system is of systemic importance. The latter are identified on the basis of the size of the financial sector and in the degree of interconnection of the banking sector with other markets and financial institutions.

Finally, in carrying out surveillance on the financial sector, the Fund is now supported by the Financial Stability Board (FSB), a body established in 1999 under the name of Financial Stability Forum and institutionalized during the G-20 in London in 2009. The task of the FSB is to monitor the financial markets' performances, to assist countries in implementing regulatory standards, to draw up emergency plans to deal with crises of systemically important cross-border financial institutions.

Overall, the reforms introduced since 2010 have had the effect of expanding the tools available to the Fund to effectively carry out surveillance activities, equipping it with new relationships (Figure 1). Those relationships could serve as a link between the two levels of supervision and allowing him to grasp the repercussions on the inside and outside of different economies policies and their interactions, the links between economic and financial policies and to improve risk assessment, while allowing, and to States Parties to have a continuous and detailed flow of information.

However, the economic literature does not fail to underline some weak points of this new architecture. In particular, for surveillance to be effective and relevant, the indications resulting from bilateral consultations or publications, produced in the framework of multilateral supervision, must be translated into concrete policy actions. To this end, it is essential that the Fund ensures that it has adequate traction, or the ability to address the economic policy choices of the Members, in the role of a trusted advisor. The address note for the 2012 IMF staff highlights how the traction has two dimensions: the first one depends on the extent to which the national authorities collaborate with the Fund regarding its analysis and its recommendations; the second one is the extent to which the indications of the IMF are applied in policy action (IMF, 2012).

Concerning the first dimension, Boormann and Ter-Minassian argued that the degree of cooperation depends on past relationships between national authorities and the IMF's staff. Thus, "Asian and Latin American authorities tend to be more critical of those from Eastern Europe and Africa, reflecting the legacy of the IMF's role in past crises in the respective regions" (Boormann and Ter-Minassian, 2014). Consequently, the authorities of the first group of countries would show a lower inclination, compared to the second group, to collaborate with the Fund during 
bilateral consultations and to perceive with more significant discomfort any suggestions aimed at the introduction of corrective measures (IEO, 2017).

About the second dimension, it also depends on effective, transparent and coherent communication of the results of the two levels of surveillance. Rogoff (2014) and Poole (2015) stressed that the "proliferation" of publications overloaded with information, not always consistent and targeted, the States Parties thus weakening the capacity of the Fund to address the economic policy choices of the Members. In particular, from the last Triennial Survey on Surveillance (TSR) in 2014 emerged as the full range of reports that the IMF makes available to Members "has become almost impossible to digest and absorb" (TSR, 2014), revealing the need for more selective communication, as regards content, and more oriented to the client.

Figure 1: IMF surveillance product timeline

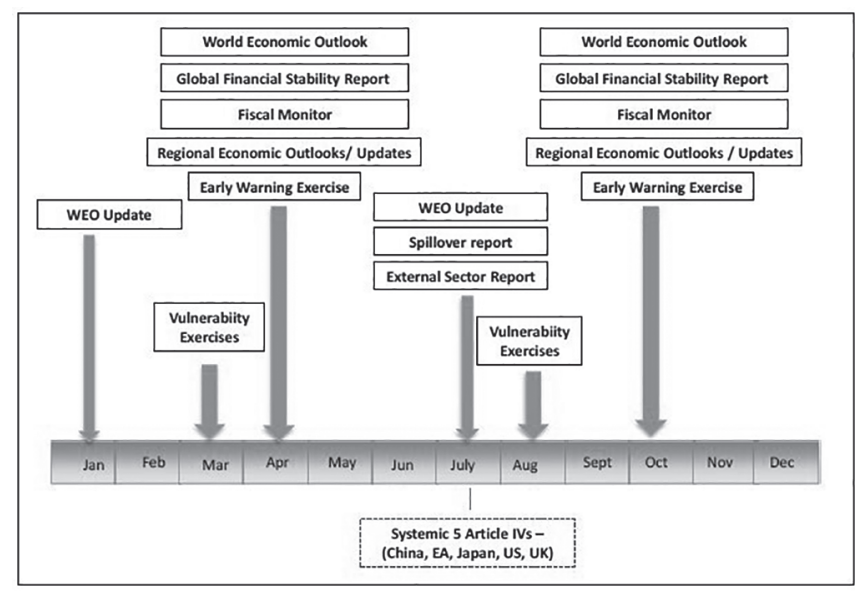

Source: Rogoff (2014).

Another weak point of the new architecture reflects a long-standing criticism of the Fund, namely the fact of not having been able to respect the principle of equal treatment among Member States. This is a particularly controversial point which undermines the very legitimacy of the institution (Callaghan, 2014) and on which the opinions of Member States diverge considerably. The achievement of this result helped the greater representation obtained by emerging countries in the governance reform of the International Monetary Fund. In fact, this led to a fairer balance of power in favor of those economies.

The aim of the introduction of those reforms is making the action of the Fund more effective in the exercise of the supervisory function, and the main purpose remains to assess that there are no fundamental imbalances in the balance of payments and to ensure stability in the currency markets. However, some point out that the action of the Fund, actually, was inadequate in facing the tensions that characterized the currency markets and, in particular, the current global imbalances. In fact, in the light of the fact that disorderly exchange rate movements that have 
occurred since the crisis and which seem to respond to competitive logic, it could seem that the Fund did not carefully verify the currency markets' performances. Likewise, the persistence of the current-account imbalances that had characterized the period before the crisis would seem to testify the ineffectiveness of the Fund's action in ensuring the "effective functioning" of the international monetary system.

\section{SURVEILLANCE OF CURRENT ACCOUNT IMBALANCES IN THE BALANCE OF PAYMENTS}

The current international economic scenario is characterized by a downsizing of the imbalances that marked the period preceding the economic-financial crisis. In particular, Figure 2 shows how, after 2008, there was a contraction of imbalances accompanied by a reconfiguration of the same in favor of the overall advanced economies considered. The latter, after recording persistent deficits for the entire period before 2008, began to exhibit current account surplus from 2011 onwards. In 2013, they surpassed Middle Eastern countries and, in 2015, also emerging Asian economies.

Figure 2: Current account balance (2000-2017, Billions of US\$)

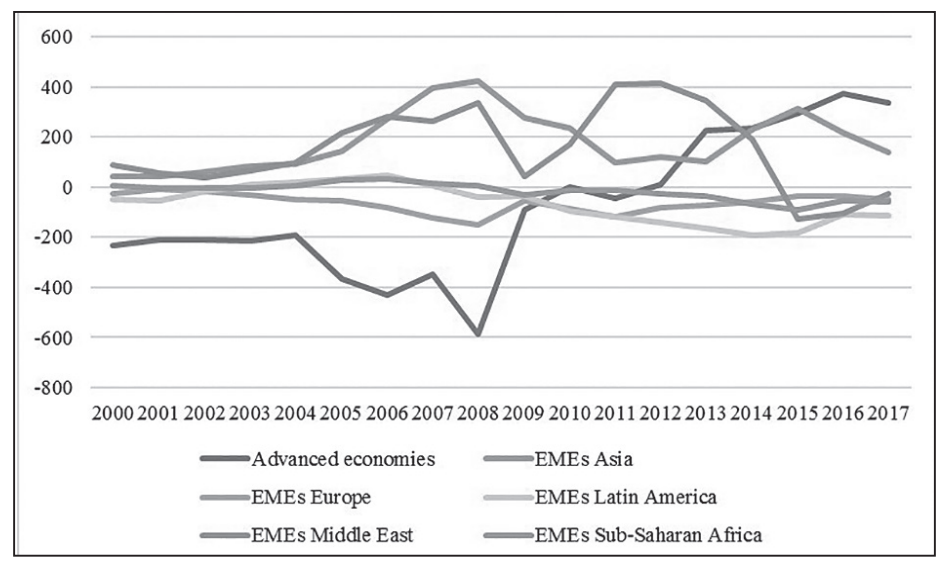

Source: WEO (2017).

Considering the configuration of the current account surpluses and deficits in more detail, Figure 3 highlights how significant changes occurred between 2008 and 2017 , especially among the surplus countries. In fact, in this period of time there has been a sharp contraction of the Chinese surplus (-64\%) and of the oil-exporting countries $(-97 \%)$ associated with an increase in Germany (32\%), which is currently the surplus of current higher part globally. On the deficit side, European countries and the US suffered a contraction - equal to $92 \%$ and $24 \%$, respectively -, while that of exporters of natural resources $(48 \%)$ continued to grow. 
Figure 3: Global imbalances (2008-2017, Billions of US\$)

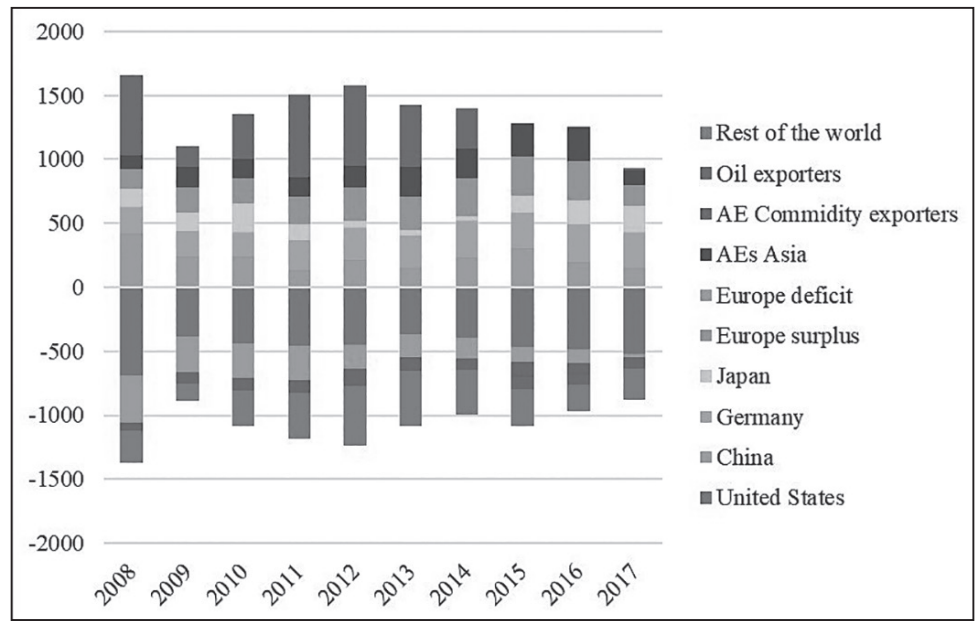

Source: WEO (2017)

Several factors have determined the reconfiguration of global imbalances. In particular, the reduction in the current account surplus recorded by crude oil exporting countries was determined by the reduction in the global oil price, which decreased vertically from the second half of 2014 to below 60 dollars per barrel (tradingeconomics.com) interrupting the long ascending phase that began in the mid-1990s. This trend reversal is due, on the one hand, to the decline in the demand for non-renewable raw materials by Eurozone and emerging countries (China and Brazil) and, on the other hand, to an over-abundant supply (WEO, 2015). The latter, in turn, was caused by the dumping policy pursued by the OPEC countries which - in connection with some geopolitical events, such as the increase in "unconventional" extractions from fracking by the United States (Hou et al., 2014), the process of reducing the sanctions that weighed on Iran and the imposition of sanctions on Russia - have increased the supply of crude oil despite the stagnation of demand, causing its price to decrease (Bchir and Pedrosa-Garcia, 2015).

The reduction of the Chinese surplus derives, instead, from a lower excess of private savings on investments, from the adoption of expansive fiscal policies, from the increase in credit and asset prices, from wage increases and the contraction of global demand (WEO, 2014). The reasons for the reversal of imbalances in favor of advanced economies have been identified, among others, in an excess of savings concentrated in Europe, especially in Germany. In particular, the hypothesis has recently been advanced based on which global imbalances would be fueled by an excess of savings concentrated mainly at European level, the so-called Euro-glut (European Commission, 2014; IMF, 2017). However, given that more than 2/3 of the European current account surplus, and therefore of the excess savings on investment, is generated by Germany, it would be more appropriate to define it as German saving glut. The sizeable German surplus - increased from 5.59\% to $8.1 \%$ of GDP between 2008 and 2017, represents a highly critical phenomenon not only 
because it negatively affects international stability, but also because it belies the expectations of convergence that they occurred at the start of EMU, favoring the spread of anti-European sentiments.

The US deficit has been reduced, going from $4.62 \%$ to $2.38 \%$ of GDP from 2008 to 2017 , but it continues to be an important source of instability, as its continuous repetition increases the risk of capital losses in which they could incurring the countries that have accumulated assets in dollars.

Overall, the international economic system continues to be characterized by persistent and fundamental imbalances in the balance of payments which, although reduced compared to the past, have focused on economies of systemic importance, posing the risk of adopting protectionist trade policies, with a consequent reduction in the global output, and measures that could compromise national or international prosperity.

In the light of these considerations, we ask ourselves what the Fund has done to identify the countries whose balance of payments has been fundamentally unbalanced and to favor adjustment.

First of all, since 2012, the IMF has developed the External Balance Assessment (EBA) methodology, which allows the identification in quantitative terms of the presence of fundamental imbalances in the balance of payments. In particular, it consists of estimating the current account balance in line with the performance of the fundamentals, with the specific elements of each country as well as with the desirable medium-long term policies. The balance value of the current account is thus obtained (current account norm) which is compared with the actual one to quantify the difference between the current and the optimal balance (current account gap, CAgap).

If the CAgap is between $\pm 1 \%$ of GDP, the country's external accounts are considered to be in line with the desirable fundamentals and policies in the medium to long term. On the contrary, the trend of an economy's external accounts is considered to be "moderately weak", "weak" or "substantially weak" if the CAgap is between $-2 \%$ and $-1 \%$, between $-4 \%$ and $-2 \%$, and higher than $-4 \%$ of GDP, respectively. Similarly, it is considered to be "moderately strong", "strong" or "substantially strong" if the CAgap is between $2 \%$ and $1 \%$, between $4 \%$ and $2 \%$, and greater than $4 \%$ of GDP, respectively (IMF, 2012b; ESR, 2017).

Applying the EBA methodology, the IMF) has identified countries with a "moderately strong" CAgap (China and Japan), "strong" (Malaysia, Korea, Sweden, Holland) and "substantially strong" (Germany, Singapore and Thailand), those with a "moderately weak" CAgap (Australia, Canada, Italy, South Africa and the United States), "weak" (Turkey, the United Kingdom, Belgium, France and Spain) and "substantially weak" (Saudi Arabia), and finally, those with a CAGAP in line with the trend of fundamentals (Brazil, Hong Kong, India, Indonesia, Mexico, Poland, Switzerland and the Eurozone). The IMF, therefore, today has adequate tools to identify the fundamental imbalances in the balance of payments and, therefore, the risks and vulnerabilities that threaten the effective functioning of the international monetary system. In this sense, the Institution provides an international public good 
signaling the presence of imbalances that, if not properly corrected, can negatively impact other economies, or create conditions of widespread instability. However, the effectiveness of the Fund's supervisory action on global imbalances depends as much on its ability to exercise adequate traction on Members as on the degree of cooperation among States in correcting them. Recalling Obstfeld "combating excess global imbalances is a joint responsibility. No single country can do it effectively on its own. All countries must act cooperatively in order that all gain. Otherwise, we leave ourselves open to the types of crises that have derailed global stability in the past" (Obstfeld, 2017).

\section{THE REFORM OF THE FINANCIAL ASSISTANCE FUNCTION}

In the context of the international financial crisis the IMF has had to face a strong demand for loans from its Members. In particular, as shown in Figures 4 and 5, IMF loans have returned to be quantitatively significant not only for developing countries, low-income ones and emerging ones but also for advanced economies. In fact, most loans are concentrated in European countries (Greece, Portugal, Ireland, Iceland, Cyprus, Hungary, Ukraine, Romania, Estonia and Poland). Therefore, it seems that the crisis led to the re-emergence of the trend observed in the first years of activity of the Fund when the financial assistance function was directed to all the Member countries and not only to a part of them. To put it in the words of Reinhart "in some sense, this most recent change brings the full circle of IMF, because advanced economies had its earliest and largest clients before emerging markets dominated its activity in the 1980s" (Reinhart and Trebesch, 2015).

Figure 4: Program incidence in advanced and developing economies (2008-2017, SDRs, billions)

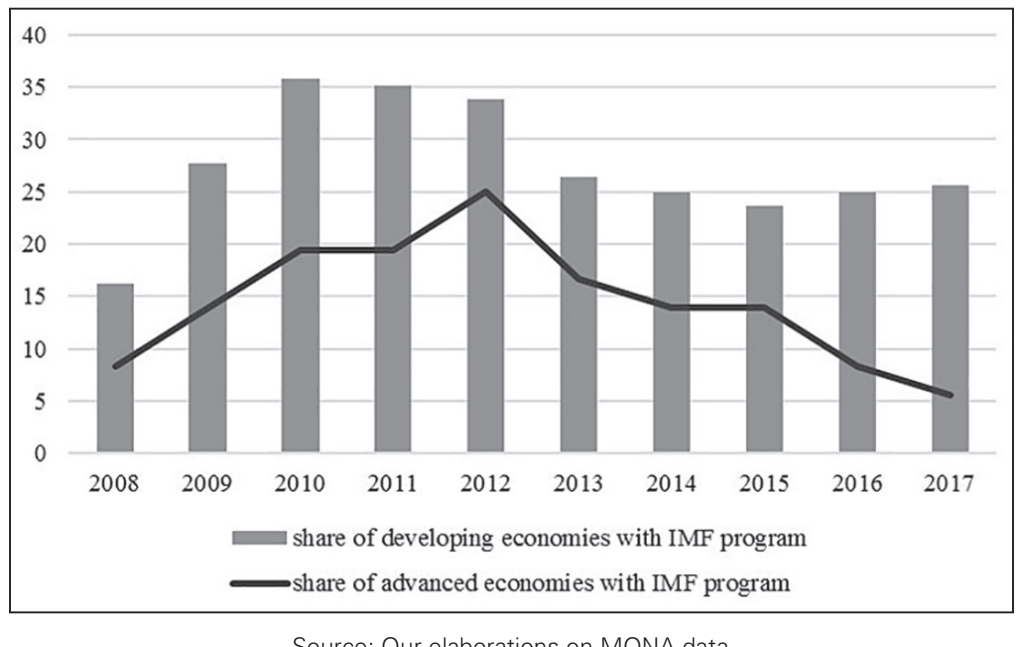

Source: Our elaborations on MONA data. 
Figure 5: Credit outstanding: regional

concentration (1970-2010, US dollar, billions)

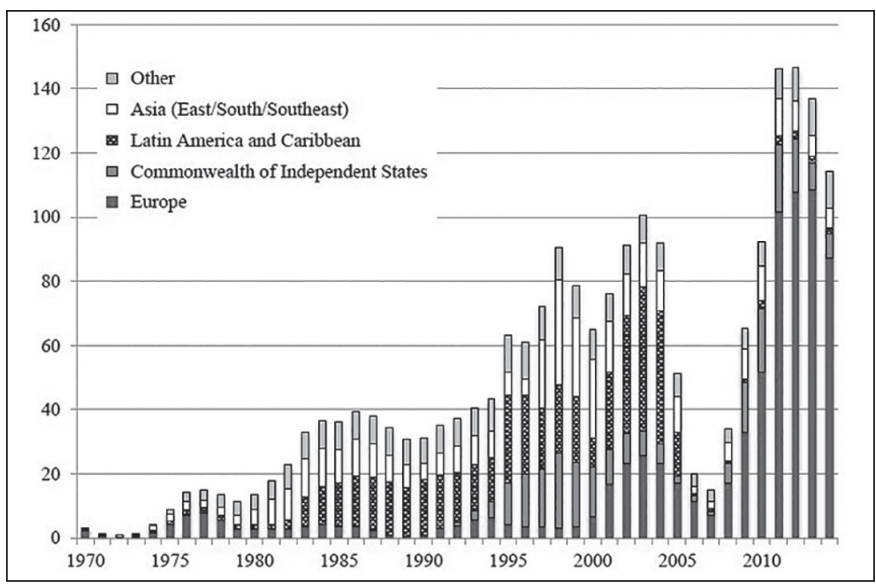

Source: Reinhart (2015).

The Executive Board, taking note of the fact that "Fund's pool of resources had become too small for its lending to be relevant to a large segment of the membership, and that its lending instruments did not provide the service that members seek, sent negative signals, and came with too many conditions, too little financing and were too costly" (IMF, 2008), it discussed ways to make the framework of funding more flexible and effective, adapting it to the changing needs of members and in compliance with adequate mechanisms to reinstate the institution's resources. The result was a profound revision of the Fund's financial assistance function, culminating in the reform implemented in March 2009 which reorganized the financial instruments, strengthening those of a precautionary nature and rationalizing those of crisis management and resolution.

To strengthen the crisis prevention role, two new facilities have been introduced: the Flexible Credit Line (FCL) and the Precautionary and Liquidity Line (PLL). These two credit lines can be used in the presence of a current or potential foreign currency requirement deriving from an imbalance in current or capital account. The FCL was introduced for the purpose of "addressing all types of payments needs and could be used for either contingent or actual financing [...] the FCL could also belp high performing members of the deal with financing pressures from the ongoing global deleveraging" (IMF, 2009), while the introduction of the PLL meets the objective of preventing or limiting the effects of contagion and, therefore, of preventing the financial difficulties faced by a single state from investing the economy of others countries and to launch a process of transmission of conditions of instability that undermine the national or international economic equilibrium (IMF, 2014). The limits of access to resources within the FCL are not fixed, but are determined from time to time based on the characteristics of the individual beneficiary countries, leaving the Fund ample discretion in determining the amount; otherwise, for the 
PLL a maximum limit of $1,000 \%$ of the quota is established, divided into tranches of an amount that varies according to the duration of the arrangement.

Furthermore, instead of resorting to the traditional ex-post conditionality, recourse to ex-ante conditionality was facilitated, or rather to the introduction of material requirements of eligibility or rather pre-qualification (qualification criteria) that States Parties must possess in order to be able to access the resources of the two new branches (Sicat, 2009). Consequently, the FCL and the PLL are intended only for members whose economy has few elements of vulnerability.

As for the PLL, the economic and institutional bases and the policies of the State that intends to access it must respond to a criterion of solidity ("sound"), and must be confirmed by a positive judgment of the external position, of the monetary, fiscal and supervision policies of the financial sector. In this context, the positive judgment formulated in the framework of bilateral surveillance and an overall assessment from which no elements of the fragility of the national economy emerge does not matter. In particular, the arrangement cannot be signed if the requesting member also presents only one of the following conditions of vulnerability: the impossibility of accessing the capital markets; the adoption of broad macroeconomic and structural adjustment policies to correct external imbalances, even only potential ones; unsustainable public debt in the medium term; widespread bankruptcy conditions in the banking sector (Magazzino et al., 2020; Magazzino et al., 2019; Magazzino and Mutascu, 2019; Brady and Magazzino, 2019; Brady and Magazzino, 2018a, 2018b, 2017a, 2017b; IMF, 2015).

As regards the various elements through which the policy of conditionality finds manifestation (prior actions, indicative targets, performance criteria, and structural benchmarks), these are completely excluded within the framework of the FCL. While the PLL, characterized by the provision of qualification criteria less stringent than those of the FCL, admits elements of conditionality ex-post, but only in the form of indicative targets and quantitative performance criteria concerning the prohibition of commercial and currency restrictions for current transactions, multiple exchange rates and delays in payments to foreign countries.

The measures described fall within the framework of strengthening the Global Financing Safety Net (GFSN) - aimed at tackling financial crises, mitigating the impact of external shocks in the form of liquidity crises or sudden stops in inflows of foreign capital - which includes bilateral currency swap agreements among central banks, regional reserve pooling agreements (Regional Financing Arrangements, RFAs), accumulation of reserves considered as self-insurance and Fund facilities (Moreno, 2013; IMF, 2014). The IMF, as a privileged forum for a multilateral cooperation, through the establishment of the aforementioned precautionary branches has also tried to pursue the objective of creating mechanisms within it to prevent excessive accumulation of reserves by the member states. However, requests for financial assistance for precautionary purposes have been rather small, despite the risks deriving from the volatility of international financial flows. The PLL was activated only in favour of Morocco, for a total of about 9 billion SDRs mainly due to the growing geopolitical instability of the region (IMF, 2014), and of Macedonia, for 
a total of about 305 million dollars (IMF, 2016), in order to provide it with the right tools to deal with the potential contagion effects due to the close commercial and financial ties with Greece, even in the absence of an effective balance of payments requirement. The reasons for the low use of the two new facilities are due to various reasons. First, it is believed that the presence of stringent material access requirements has inhibited requests for access by Members (IEO, 2014; IMF, 2014). In the second place, "the relatively modest use of the FCL and the PLL reflected a number of members and remaining perceptions of stigma associated with financing in general" (IEO, 2014, p. 22). However, in this case, the "stigma" connected to the use of the Fund's financial assistance seems to respond more to previous policy evaluation deriving from the often negative consequences that the programs sponsored by the Fund have produced on the economic and social fabric of the beneficiary members. In fact, the authorities of the countries that have had access to the aforementioned facilities have actually expressed a positive judgment on both, underlining how they have been able to provide "the right incentives for countries to follow the right policies, representing an important effort to boost the effectiveness of the IMF lending toolkit [...] Authorities from FCL and PLL countries also that this instrument is able to overcome existing stigma concerns and facilitated the domestic political discussion on the implementation program, indicating that without the new instruments there would not have any program because of the political stigma associated with SBAs" (IEO, 2014).

Therefore, even if the "stigma" problem continues to weigh on the precautionary instruments of the Fund, its activity in the context of global safety nets is weakened and, consequently, the decisive role that the institution, through financial assistance, could play doing away with the incentive to accumulate reserves beyond the optimal level (IEO, 2014).

In the context of the crisis management and resolution function, the 2009 reform led to an increase in the size of credit lines, rationalization and simplification of traditional financial assistance desks and introduced a more flexible approach to conditionality.

Concerning the first point, the 2009 reform has raised the limits set by art. V section 3, letter (b) (iii), providing that within a year the States may resort to the general resources of the IMF for a maximum amount equal to $200 \%$, and on a cumulative basis up to $600 \%$ of their quota (Moreno, 2013).

About the second point, the little-used branches were discontinued, such as the Supplemental Reserve Facility, the Compensatory Financing Facility, and the Short-term Liquidity Facility, leaving only the SBAs and EFFs unchanged. The policy of conditionality finds its full application here, since, according to the approach followed by the IMF, the beneficiary States lack the macroeconomic and structural characteristics that can justify a lesser rigor in defining the corrective measures aimed at correcting the imbalances. However, in relation to this last aspect, the Fund, responding to the requests of emerging countries, has established that the provision of financial assistance must be based on an overall assessment of the progress made by the beneficiary Members in the framework of an arrangement 
rather than on compliance with specific conditions (IMF, 2016). In addition, the International Monetary Fund has decided to not subordinate access to its resources to the satisfaction of structural performance criteria, due to two considerations: the impossibility of always identifying objective parameters for their measurement and awareness that they are perceived by the States as instruments of excessive interference in the management of economic policies, especially with regard to the adoption of measures that cannot be traced back to the "core responsibility areas" of the Institution. Consequently, for the balance-of-payments support decisions approved after 2009, the elements of structural conditionality are envisaged in terms of prior actions and structural benchmarks, understood by the 2002 guidelines, as measures that cannot be objectively measured or not considered sufficiently to influence the right to withdraw foreign currency.

Finally, the 2012 conditionality review produced a series of recommendations aimed to maintaining the conditionality focused on measures strictly functional to the pursuit of the objectives of an adjustment program; to strengthen risk analysis by improving coordination with the analyses deriving from the surveillance function; to also consider the social aspects by weighting the analysis of long-term benefits with that of short-term costs; to strengthen ownership taking into account the specific circumstances occurring in the beneficiary Member and, finally, to complete collaboration with other international organizations, including currency unions, mainly when the success of an adjustment program depends on the policies implemented at the level of union (IMF, 2011a).

Starting from these premises, we will discuss in the next section if the IMF has returned to perceive conditionality as an undue mission creep.

\section{CONDITIONALITY IN THE IMF PROGRAMS}

\section{AFTER THE 2008 FINANCIAL CRISIS}

In order to analyse the policy of conditionality there are two approaches: a) the first one consists in determining the degree of intrusiveness of the Fund's policies in the internal affairs of the members (the total number of conditions, as well as their distribution in the various areas of competence Institutions); b) the second one uses the concept of structural depth to assess whether structural conditionality clauses are or are not essential in order to achieve the goals of an adjustment program.

\section{The criterion of intrusiveness}

Following the first approach in Figure 6, we reported the total number of conditions applied to the 86 countries (see the Appendix) which in the 2008-16 period had access to one of the Fund's credit lines. As can be seen in the graph, the total number of conditions increased between 2008 and 2010, the years in which, due to the need for "tackle-rooted issues, such as competitiveness or large debt burden" (IMF, 2012c), reached the maximum value of about 2,000 conditionality clauses 
and then progressively decreased starting from 2011 and reaching the minimum value of about 600 in 2015 . Overall, the total number of conditions applied to the recipient countries of a program in the post-crisis period was found to be lower than the pre-crisis one. Since the total number of conditions is used as a unit of measurement of the principles of parsimony, which implies that the conditionality clauses must be strictly functional to the pursuit of the objectives of the adjustment programs, and the clarity, or be formulated so as to allow clearly identifying the constraints to which access to the institution's resources is subject, it follows that in recent years there has been an attempt by the Fund to fully implement the aforementioned two principles established by the 2002 guidelines on conditionality.

Figure 6: Total number of condition (2008-2016)

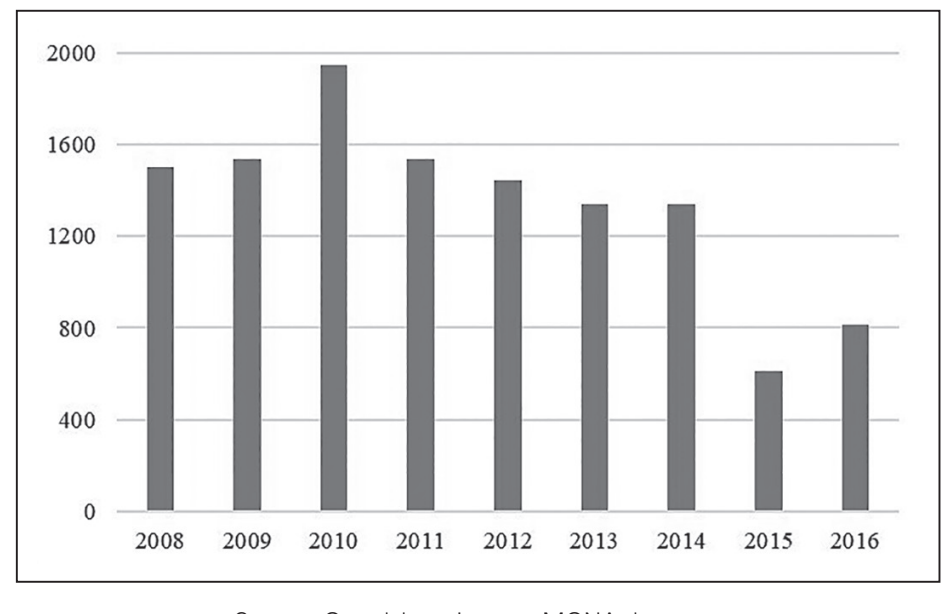

Source: Our elaborations on MONA data.

Cross-compliance tools and their use by the Fund have also changed over time. Figure 7 shows the average number of conditions distinguishing among quantitative performance criteria (QPCS), structural performance criteria (SPCs), structural benchmarks (SBS) and prior actions (PAs). Furthermore, there is a longer period considered in order to grasp more adequately the changes that occurred, especially in the application of structural conditionality clauses (SC). From the analysis of Figure 7 it is possible to draw some considerations. First, the QPCs remain the tools most used by the IMF and their number, after an increase in 2008-2010, they started to decrease again, reaching around an average value of 8 QPCs per program. Secondly, the use of structural conditionality clauses has been reduced compared to the pre-crisis period, passing from 6.21 average structural conditions per program from 2002-2008 to 2.21 from 2008-2016. This lower use of structural conditionality seems to have contributed significantly to the decision taken by the Fund in 2009 to remove the structural performance criteria from the list of SC instruments as much as the tendency to use more sparingly, compared to the past, both the PAs that the SBs. 
Figure 7: Average number of conditions per program

year by type of condition (2002-2016)

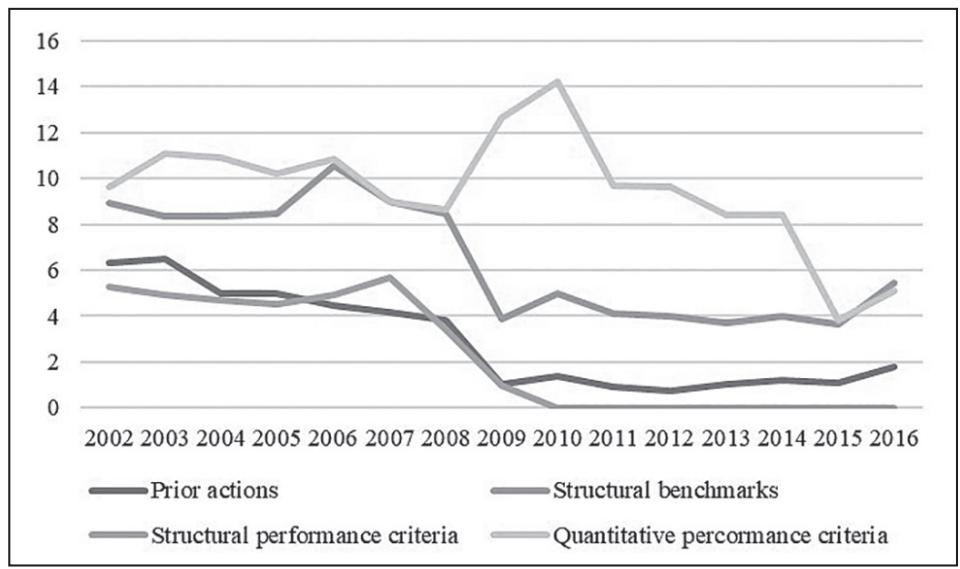

Source: Our elaborations on MONA data

In order to understand if the institution has continued to adopt a less extensive vision of its role by applying the structural conditionality clauses in its competence areas - as happened before the crisis - we analysed their distribution in those sectors that were affected most by the reform, as part of an adjustment program to assess whether they fall within the cores in shared or non-core responsibilities areas. The analysis of Figures 8 and 9 confirms the trend recorded in the period preceding the economic and financial crisis. In fact, in the period 2008-2016, in the programs of the Fund globally considered the percentage of structural conditions falling within the core responsibility areas of the Institution was equal to about $72 \%$, while the percentage concerning the shares and the non-core responsibility areas were at $19 \%$ and $7 \%$, respectively. In particular, Figure 8 shows that in the 2008-2016 period $29 \%$ of the conditionality clauses were applied to fiscal policy, $18 \%$ to the management of public resources, $25 \%$ to the regulation and supervision of financial markets, to monetary policy and of the exchange rate, $12 \%$ to the privatization of public enterprises, $7 \%$ to the reform of social security systems and $7 \%$ to labour market policies, in order to fight poverty and to all those measures used to respond to structural weaknesses in specific economic sectors such as the primary one.

By analyzing the subsidized loans (those granted through the Poverty Reduction and Growth Trust) and the non-subsidized ones (the financial ones through the General Resource Account, GRA), it is possible to assert that the structural conditionality clauses are concentrated mainly in the areas of main responsibility of the Fund, although there has been a slight reduction in both programs between 2008-2012 and 2013-2016 (Figure 8). More specifically, in the loans granted through the GRA the core reform areas constituted $60 \%$ of the total structural clauses in 2008-2012 and 57\% in 2013-2016; while in the programs financed through the PRGT recorded a decrease of about 3 percentage points, from $74 \%$ to $71 \%$. Furthermore, the clauses included in the competencies shared between the Fund and other organizations were $25 \%$ in 2008-2012 and 32\% in 2013-2016 in the GRA- 
supported programs. In the PRGT-supported programs, they have increased from $18 \%$ to $20 \%$ from $2008-2012$ to $2013-2016$.

Figure 8: Distribution of structural conditionality by economic sector (2008-2016, percent of total structural conditions)

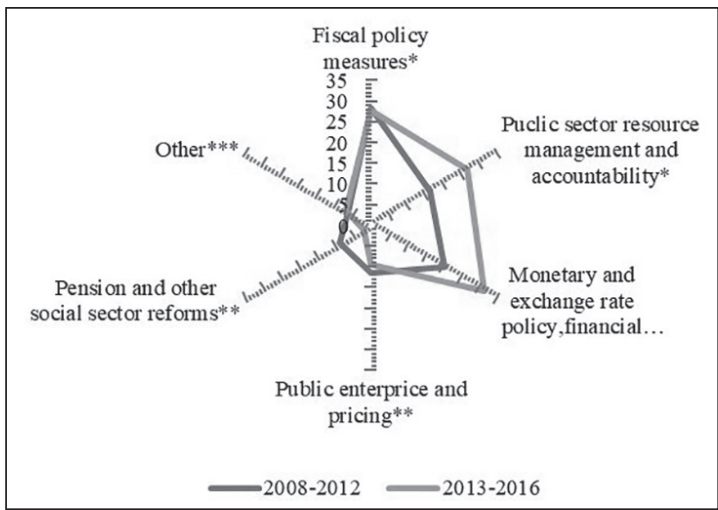

Source: Our elaborations on MONA data. Notes: ${ }^{*}$ core responsibility areas,

** shared responsibility areas, *** non-core responsibility areas.

Figure 9: Breakdown of structural conditionality into IMF competencies (2008-2016, as a share of structural conditionality per program year)

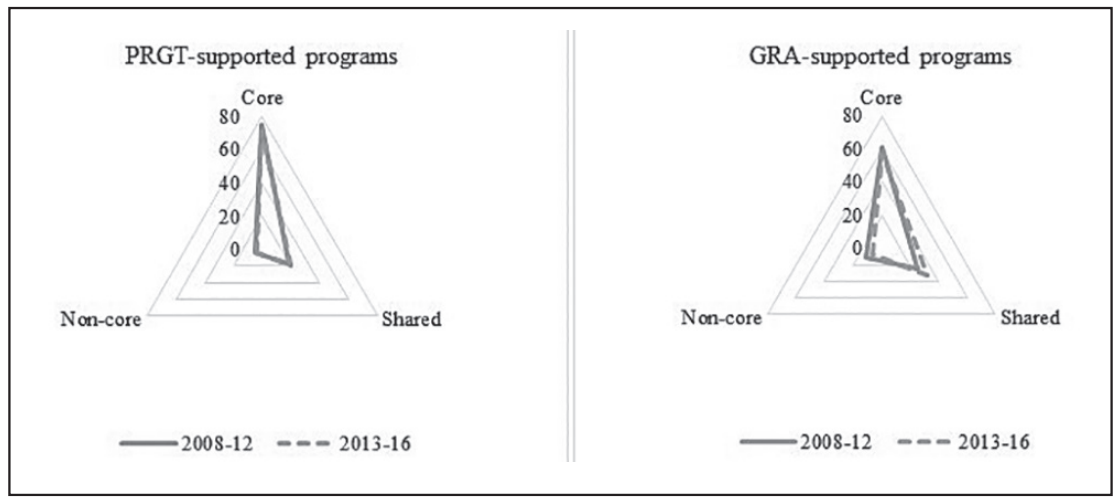

Source: Our elaborations on MONA data.

In both cases, the structural clauses not falling within the competence of the Institution represented a marginal component of the conditionality, settling around $6 \%$ in loans financed through the GRA and $5 \%$ in those granted through the PRGT.

\section{The structural depth}

The IMF (2012b) estimated the structural depth (SD) of the conditionality by distinguishing the structural conditions according to whether they present a low (low 
structural depth), an average (medium structural depth) or a high (high structural depth) SD. The first category includes all those structural conditions which are not likely to produce structural changes and which, consequently, are not essential for achieving the goals of a program. The second one includes all those clauses that can potentially induce structural changes, but only if repeated over time. Finally, part of the third category are all those structural conditions which, profoundly affecting the economic structure of the receiving country, can be considered of critical importance to achieving the objectives of a program.

The analysis of the Fund came to the following conclusion:

" 47 percent of measures fall into the first category, 29 percent into the second category and 24 percent into the third category [...] Structural depth varied among economic sectors: conditionality related to labor market policies, a non-core area of Fund-supported programs, was limited, and most conditions fell into the lowest category of structural depth. By contrast, conditionality linked to public enterprise reform, pensions and other social sector reforms, other structural reforms, trade policy, and, in particular, exchange systems showed a high degree of structural depth. Overall, structural depth was more pronounced in GRA programs than in PRGT Programs. Over time, both PRGT and GRA conditionality was marked by a trend toward higher structural depth" (IMF, 2012d).

Therefore, our analysis confirms the positive data of a lower interference of the Fund in areas outside its mandate and of a higher concentration of programs in the areas of its competence, in which its work manages to be more effective. Furthermore, given that a growing percentage of structural conditionality clauses has a high degree of impact on the economic structure of the beneficiary countries, it follows that many of the conditions set are "sufficiently critical" to achieve the objectives of a program.

\section{CONCLUSIONS}

From the analysis carried out in the course of this paper, the limits that still exist in the action of the Fund concern especially the supervisory activity emerged.

In fact, the innovations introduced since 2010 had the effect of expanding the tools available to the institution to effectively carry out its surveillance function. Nevertheless, the international economic system continues to be characterized by persistent imbalances which, although reduced compared to the past, have been concentrated in systemically important economies, posing the risk of implementing measures that could compromise national and international prosperity. Concerning the financial assistance function, it was illustrated how the needs imposed by the 2008 economic and financial crisis led the Institution to reorganize the financial 
instruments, strengthening those of a precautionary nature and rationalizing those of crisis management and resolution. The starting point of the new architecture was the awareness that the previous crisis management, especially those of South-East Asia, had left a profound "stigma" connected to the use of the Fund's financial assistance deriving from the often negative consequences of the programs sponsored by it had produced on the economic and social fabric of the beneficiary Members. Thus, alongside the traditional conditionality based on the a posteriori implementation of adequate economic policies, a criterion of ex ante conditionality in the precautionary branches was also introduced, based on the economic characteristics of the country to be financed. Concerning ex ante conditionality we highlighted how it has been inserted in the context of strengthening the "global safety nets" aimed, among others, at limiting the excessive accumulation of foreign exchange reserves. The Fund, as a privileged forum for a multilateral cooperation, has attempted to create within it some mechanisms to prevent it by making two new credit lines available to Members, which can be used in the presence of a current or potential foreign currency requirement deriving from an imbalance in the current or capital account. However, requests for financial assistance for precautionary purposes have been quite small, despite the risks deriving from the volatility of international financial flows, thus demonstrating the fact that there is still a problem of "stigma" that would penalize the countries that make use of the Fund, even if only for precautionary purposes. Therefore, the activity of the IMF in the context of "global safety nets" is weakened and, consequently, the positive role that the Institution, through financial assistance, could play by eliminating the accumulation of reserves beyond the optimal level.

The "traditional" conditionality was examined along two lines: on the one hand, an attempt was made to show whether that the Fund continued to respond effectively to the criticism of the mission creep, adopting, in the light of the principles established in the guidelines on conditionality, an extensive visionless role and, on the other hand, to assess whether the institution has actually introduced a more flexible approach using the elements of structural conditionality. From our analysis, we observed that the number of structural conditions has decreased compared to the past. This gave effect to the principles of parsimony and clarity, according to which the structural clauses should be strictly functional to the pursuit of the objectives of an adjustment program and be formulated, so as to identify the constraints to which access to the IMF' $s$ resources is subjected. Furthermore, the elimination of the structural performance criteria, perceived by the states parties as instruments of excessive interference in the management of economic policies - together with the lesser use of structural benchmarks, referring to variables or measures that cannot be verified in objective terms, and to the prior actions - seems to suggest that also the owner of the programs has been strengthened in the period following the economic and financial crisis and that the Fund has effectively adopted a more flexible approach to structural conditionality, privileging the overall evaluation of the progress made by the beneficiary members in the framework of an arrangement in compliance with specific conditions. Our analysis confirmed the positive data of a lower interference of the Fund in areas outside its mandate and of a higher concentration of programs in the areas of its competence, in which its work manages to be more effective. 
Finally, given that a growing percentage of structural conditionality clauses presented a high degree of incidence on the economic structure of the beneficiary countries, it follows that many of the conditions set are "sufficiently critical" to achieve the objectives of a program.

\section{REFERENCES}

Adinolfi G. (2012). Poteri e Interventi del Fondo Monetari Internazionale. Cedam, UTET.

Bchir M.H., Pedrosa-Garcia J.A. (2015). “The Impact of the 2014 Oil Price shock on Arab Economies". ESCWA's Survey on Economic and Social Development in Arab Region.

Boormann J., Ter-Minassian T. (2014). 2014 Triennal Surveillance Review - External Study, Report on Interviews. Washington: International Monetary Fund.

Brady, G.L., Magazzino, C. (2017a). "Sustainability of Italian Budgetary Policies: A Time Series Analysis (1862-2013)". European Journal of Government and Economics.

Brady, G.L., Magazzino, C. (2017b). “The Sustainability of Italian Public Debt and Deficit”. International Advances in Economic Research, 23, 1, 9-20.

Brady, G.L., Magazzino, C. (2018a). "Fiscal sustainability in the EU”. Atlantic Economic Journal, 46, 3, 297-311.

Brady, G.L., Magazzino, C. (2018b). "Sustainability and co-movement of Government Debt in EMU Countries: A Panel Data Analysis”. Southern Economic Journal, 85, 1, 189-202.

Brady G.L., Magazzino C. (2019). “The sustainability of Italian fiscal policy: myth or reality?”. Economic Research-Ekonomska Istraživanja, 32, 1, 772-796.

Callaghan M. (2014). "Even handedness of Fund Surveillance”. IMF Policy Paper.

European Commission (2014). "What drives the German current account? And how does it affect other EU member states?”. Economic Paper, 516, April.

Hou, Z., Granoff, D., Granoff, I., Keane, J., Kennan, J., Norton, A., Velde, D.W. (2014). “The development implications of the fracking revolution". ODI Working Paper.

Independent Evaluation Office (2006). Multilateral Surveillance, Evaluation Report.

Independent Evaluation Office (2013). The Role of the IMF as Trusted Advisor, Evaluation Report.

Independent Evaluation Office (2017). IMF Exchange Policy Advice, Evaluation Update.

International Monetary Fund (2008). "Reform of Quota and Voice in the International Monetary Fund, Draft Report of the Executive Board to the Board of Governors”, IMF Policy Paper, March.

International Monetary Fund (2009). "Integrating Financial Sector Issues and FSAP Assessments into Surveillance”. Progress Report.

International Monetary Fund (2010). "Modernizing the Surveillance Mandate and Modalities”. IMF Policy Paper, March.

International Monetary Fund (2010). "Regional Financial Safety Nets to Create Stronger Links". IMF Survey Magazine: Policy, October.

International Monetary Fund (2010). "Reserve Accumulation and International Monetary Stability". IMF Policy Paper, April.

International Monetary Fund (2011). “Triennial Surveillance Review - Overview Paper”. IMF Policy Paper, August.

International Monetary Fund (2012a). "Review of Conditionality - Overview Paper”. IMF Paper, June. International Monetary Fund (2012b). "Review of Conditionality - Background Paper 1: Content and Application of Conditionality". IMF Paper, June.

International Monetary Fund (2012c). External Balance Assessment (EBA): Technical Background of the Pilot Methodology. Washington: IMF.

International Monetary Fund (2012d). "Review of Conditionality - Background Paper 2: Design of Fund-Supported Programs”. IMF Paper, June.

International Monetary Fund (2014a). Press Release No 14/368. IMF Paper.

International Monetary Fund (2014b). Triennial Surveillance Review. IMF Paper, July. 
International Monetary Fund (2015). "Guidance Note for Surveillance under Article IV Consultation”. IMF Paper, May.

International Monetary Fund (2016). "Conditionality Factsheet”. IMF Paper, April.

International Monetary Fund (2017). "External Sector Report”, IMF Policy Paper, July.

International Monetary Fund (2017c). "Spillover Report". IMF Paper.

International Monetary Fund (2017d). World Economic Outlook, Washington D.C.: IMF.

Magazzino, C., Forte, F., Giolli, L. (2020). “On the Italian public accounts' sustainability: a wavelet approach". International Journal of Finance \& Economics.

Magazzino, C., Brady, G.L., Forte, F. (2019). "A panel data analysis of the fiscal sustainability of G-7 countries". The Journal of Economic Asymmetries, 20.

Magazzino, C., Mutascu, M., (2019). “A wavelet analysis of Italian fiscal sustainability”. Journal of Economic Structures, 8, 19.

Moreno, P. (2013). "The Metamorphosis of the IMF (2009-2011)". Banco de Espana-Estudios Economicos, 78 .

Poole, E. (2015). “The IMF’s ‘Surveillance’: How Has It Changed since the Global Financial Crisis?”. Reserve Bank of Australia.

Reinhart C., Trebesch, C. (2015). “The International Monetary Fund: 70 Years of Reinvention”. NBER Working Paper, 21805.

Rogoff, K. (2014). “2014 Triennial Surveillance Review - External Study- Integrating Bilateral and Multilateral Surveillance on a Continuing Basis". IMF Policy Paper, July.

Sicat, T.I. (2009). "IMF's Flexible and Precautionary Credit Lines - Alternative to Reserve Accumulation?”. Bangko Sentral Review, 48-51.

\section{APPENDIX}

Countries included in our analysis: Afghanistan, Albania, Algeria, Angola, Antigua and Barbuda, Saudi Arabia, Argentina, Armenia, Azerbaijan, Australia, Austria, Bahamas, Bahrain, Bangladesh, Barbados, Belgium, Belize, Benin, Belarus, Bolivia, Botswana, Brazil, Brunei Darussalam, Burkina Faso, Bulgaria, Burundi, Bhutan, Cambodia, Cameron, Canada, Cape Verde, Chad, China, Cyprus, Colombia, Comoros, Korea, Costa Rica, Croatia, Denmark, Djibouti, Dominica, Ecuador, Egypt, El Salvador, United Arab Emirates, Eritrea, Estonia, Ethiopia, Eurozone, Fiji, Philippines, Finland, France, Gabon, Gambia, Georgia, Germany, Ghana, Jamaica, Japan, Jordan, Greece, Grenada, Guatemala, Guinea Bissau, Equatorial Guinea, Guyana, Haiti, Honduras, Hong Kong, India, Indonesia, Iran, Iraq, Iceland, Marshall Islands, Solomon Islands, Israel, Italy, Kazakhstan, Kenya, Kiribati, Kuwait, Kyrgyz, Laos, Lesotho, Latvia, Lebanon, Liberia, Libya, Lithuania, Luxembourg, Macao, Macedonia, Madagascar, Maldives, Malaysia, Malta, Mexico, Moldova, Montenegro, Mozambique, Myanmar, Nepal, Nicaragua, Niger, Nigeria, Norway, Holland, Oman, Pakistan, Panama, Papua New Guinea, Paraguay, Peru, Poland, Portugal, Qatar, United Kingdom, Czech Republic, Slovakia, Central Republic - Africa, Republic of the Congo, Democratic Republic of the Congo, Dominican Republic, Romania, Russia, Rwanda, Samoa, Sao Tome and Prince, Senegal, Serbia, Seychelles, Sierra Leone, Singapore, Spain, Sri Lanka, St. Kitts and Nevis, St. Lucia, United States of America, South Africa, Sudan, Suriname, Sweden, Switzerland, Thailand, Taiwan, Tajikistan, Tanzania, Timor-Leste, Togo, Tonga, Trinidad and Tobago, Tunisia, Turkey, Turkmenistan, Tuvalu, Ukraine, Uganda, Hungary, Uruguay, Uzbekistan, Vanuatu, Venezuela, Vietnam, Yemen, Zambia, Zimbabwe. 